\title{
Análise Econômica do Sistema Intensivo de Suínos Criados ao Ar Livre ${ }^{1}$
}

\author{
Denyse Maria Galvão Leite ${ }^{2}$, Osmar Antonio Dalla Costa ${ }^{3}$, Gilberto Alexandre Vargas 4 , \\ Roger Daniel de Souza Milleo ${ }^{5}$, Aparecido da Silva ${ }^{2}$
}

\begin{abstract}
RESUMO - Foi instalado um Sistema Intensivo de Suínos Criados ao Ar Livre (SISCAL), na Estação Experimental de Pato Branco do Instituto Agronômico do Paraná, com o objetivo de determinar os custos de implantação e produção deste sistema, na região Sudoeste do Paraná. A área do SISCAL foi dimensionada para um plantel de 14 matrizes e um reprodutor, a qual foi dividida em piquetes para separar os animais por estágios fisiológicos (reprodução, gestação e creche). O custo de implantação foi baseado nos custos de mão-deobra e dos materiais utilizados para instalação do sistema e confecção de alguns equipamentos, como também os custos da construção da fábrica e depósito de ração e dos equipamentos para confecção das rações. O custo total de implantação do SISCAL, excluindo o valor da terra, foi de US\$6862,80, ou seja, US\$ 490,20 por matriz instalada, em julho de 1997. A construção e os equipamentos da fábrica de ração foram os itens mais caros do custo de implantação. O custo total de produção por kg de leitão desmamado produzido foi US\$ 0,617, em junho de 1999. Neste período, foi possível obter $18,81 \%$ de lucro líquido por kg de leitão produzido.
\end{abstract}

Palavras-chave: custo fixo, custo total, custo variável, margem líquida

\section{Economic Analysis of an Outdoor Pig Production System}

\begin{abstract}
An Outdoor Pig Production System (SISCAL), at the Experimental Station Agronomic Institute of Paraná State was used with the objective to determine the establishment and production costs of this system in the Southwestern region of Paraná. The SISCAL area was dimensioned to a 14 sows and one boar herd, which was divided in paddocks to separate the animals per physiological stage (reproduction, gestation and nursery). The establishment cost was based on the labor, material used for the system installation and the manufacturing of some equipment, as well as the feed plant and storage construction costs and equipments for the ration production. The total establishment observed cost of the SISCAL, excluding capital value of land, was of US\$ 6862.80 or US\$ 490.20 per housed sow, in July 1997. The feed plant and storage construction costs as well as the equipments were the items that increased the establishment cost most. The production cost per $\mathrm{kg}$ of weaned pig was US\$ 0.617 in June 1999. In this period it was possible to get an $18.81 \%$ of net income per $\mathrm{kg}$ of produced pig.
\end{abstract}

Key Words: fixed cost, total cost, variable cost, net income margin

\section{Introdução}

Diante da atual situação e das mudanças socioeconômicas que vêm pressionando os suinocultores a melhorarem a qualidade de seus produtos para atender as exigências de mercado, surge a necessidade de se buscarem alternativas tecnológicas que reduzam os custos de produção, não demandem altos investimentos de recursos financeiros e possibilitem a obtenção de bons índices de produtividade.

Em consequiência disso, o Sistema Intensivo de Suínos Criados ao Ar Livre (SISCAL) vem se expandindo em vários países, por apresentar bom desempenho técnico, baixo custo de implantação e manutenção, facilidade de ampliação da produção em comparação aos sistemas confinados, como também devido à crescente preocupação com o bem-estar animal e os possíveis benefícios conseqüentes à comercialização (EDWARDS e ZANELLA, 1996).

Segundo ZANELLA (1996), o declínio da produtividade de cereais, no Reino Unido, tem incentivado a adoção de suínos ao ar livre em áreas agrícolas. Cerca de $20 \%$ das porcas, no Reino Unido, têm sido alojadas ao ar livre. Já na região Sudeste dos Estados Unidos e na França, cerca de 10\% das porcas estão sendo criadas ao ar livre (Le DENMAT et al., 1995 e McGLONE, 1996) e na Dinamarca e na Suécia estão sendo desenvolvidos alguns projetos pilotos (MORTENSEN et al., 1994).

No Brasil, o SISCAL, com o objetivo de produzir

\footnotetext{
1 Trabalho realizado em parceria - Instituto Agronômico do Paraná-IAPAR e o Centro Nacional de Pesquisa de Suínos e Aves - CNPSA/EMBRAPA 2 IAPAR - Cx. Postal 510, CEP 85505-970, Pato Branco - PR. E.mail: dmgleite@pr.gov.br

3 CNPSA/EMBRAPA- Cx. Postal 21, CEP 89700-000, Concórdia-SC. E.mail: osmar@cnpsa.com.br

4 Bolsista PIBIC/CNPq - Estudante de agronomia do CEFET, Pato Branco-PR.

5 IAPAR - Cx. Postal 129, CEP 84001-970, Ponta Grossa - PR.
} 
leitões, vem sendo adotado por pequenos e médios produtores, principalmente da região Sul. Porém, segundo o estudo de análise de prospectiva do complexo agroindustrial de suínos, realizado por GOMES et al. (1992), este sistema representa menos de $1 \%$ das criações de suínos.

As unidades de produção de suínos ao ar livre, implantadas no Brasil, parecem semelhantes às da França e do Reino Unido, onde os animais têm sido mantidos em piquetes nas fases de reprodução, lactação e creche. Os leitões ao atingirem em torno dos 20 a 25 $\mathrm{kg}$ de peso vivo têm sido vendidos para serem terminados em confinamento por outros suinocultores.

O custo do sistema de criação de suínos confinado tem sido elevado e atingido valores de até US\$ 3700 por matriz instalada, na Europa (THORNTON, 1990), até US\$ 2500 por matriz instalada, na Argentina (SPINER e BRUNORI, 1995) e até US\$ 700 por matriz instalada, no Brasil ( DALLA COSTA et al. (1995), enquanto têm sido verificado valores menores por matriz instalada no SISCAL, US\$ 700 (THORNTON, 1990), entre US\$ 156 e 312 (EDWARDS e ZANELLA,1996) e entre US\$ 400 e 800 (SPINER e BRUNORI, 1995).

O custo de implantação do SISCAL é bem inferior ao sistema confinado, mas é importante salientar que os equipamentos no SISCAL têm pouca durabilidade, ao comparar com o sistema confinado (MORTENSEN et al., 1995). De acordo com McGLONE (1996), os equipamentos de uma unidade ao ar livre são depreciados entre 8 e 10 anos, porém, em uma unidade confinada, a vida útil das instalações é cerca de 20 anos e dos equipamentos (comedouros, cerca etc), entre 8 e 10 anos.

De acordo com DALLA COSTA e SANTOS (1996), a suinocultura ao ar livre só será viável, quando o preço da saca do milho for menor que US $\$ 9,90$. Os mesmos autores relataram que se a saca de milho estiver ao redor de US $\$ 6,60$, o produtor poderá ter um plantel de 44 matrizes, atingindo lucratividade máxima.

DALLA COSTA et al. (1995) verificaram que o SISCAL instalado em dois hectares apresentou margem líquida anual de U\$\$2067,87, enquanto o sistema confinado com milho teve um lucro de U\$\$ 342,21 e com o feijão, U\$ \$69,02.

Como são poucas as unidade de produção de suínos ao ar livre, no Brasil, as informações têm sido bastante limitadas. Portanto, há necessidade de verificar a viabilidade técnica e econômica do SISCAL nas diversas regiões do país. Dessa forma, o objetivo do presente trabalho foi determinar o custo de implantação e produção do SISCAL, na região Sudoeste do Paraná.
Material e Métodos

O sistema foi implantado numa área de $18060 \mathrm{~m}^{2}$, em Latossolo Bruno Roxo Distrófico, com declividade de 6,5\%. A área foi nivelada e o solo preparado com uma aração e duas gradagens com tração motorizada. O plantio da estrela africana cv IPEAME (Cynodon nlemfuensis) foi feito por mudas, distribuídas em sulcos com espaçamento de $50 \mathrm{~cm}$.

O número e a área dos piquetes foram estabelecidos para 14 fêmeas híbridas (LW x LD) e um macho da raça Duroc, de acordo com o cronograma de cobertura (a cada 21 dias). O sistema foi constituído de 10 piquetes, sendo divididos da seguinte forma: um piquete de reposição - $500 \mathrm{~m}^{2} /$ animal; dois piquetes de pré-cobrição - $800 \mathrm{~m}^{2} / \mathrm{animal}$; três piquetes de gestação - $900 \mathrm{~m}^{2} /$ animal; dois piquetes de maternidade ou lactação $-1000 \mathrm{~m}^{2} /$ animal e dois piquetes de creche $-80 \mathrm{~m}^{2} /$ leitão. A área total para cada piquete de pré-cobrição, gestação e maternidade foi estabelecida para duas fêmeas e a do piquete de creche, para 20 leitões. Cada piquete foi subdividido em três partes iguais para realização do pastoreio rotativo.

Os piquetes de maternidade foram cercados com três fios de arame ${ }^{\circ} 16$, dispostos a 15, 30 e $60 \mathrm{~cm}$ do solo, e continham cabanas individuais do tipo chalé de dimensões 3 x 1,7 x 1,45 (largura x comprimento $\mathrm{x}$ altura), abrigos rústicos individuais $(2,0 \mathrm{~m} \mathrm{x} \mathrm{2,0} \mathrm{m)}$ e um comedouro de madeira com cobertura de zinco para as fêmeas e outro para os leitões.

Os piquetes de creche foram cercados com tela de arame de $40 \mathrm{~cm}$ de altura e um fio de arame $\mathrm{n}^{\circ} 16$ disposto a $15 \mathrm{~cm}$ do solo e colocado na parte interna do piquete. Cada piquete continha uma cabana do tipo chalé de dimensões $3 \times 2,9 \times 1,45$, um abrigo rústico $(2,0 \mathrm{~m} \times 2,0 \mathrm{~m})$ e um comedouro de madeira com cobertura de zinco.

Em cada piquete de gestação, pré-cobrição, reposição e do reprodutor, foi colocado um comedouro circular feito de pneu de caminhão e madeira, para fornecimento de ração controlada, e um abrigo rústico $(2,0 \mathrm{~m} \times 2,0 \mathrm{~m})$. Todos os subpiquetes possuíam bebedouros tipo chupeta.

Para o cálculo do custo de implantação, foi considerada a construção de uma fábrica e depósito de ração de $24 \mathrm{~m}^{2}$, feitos de madeira com base de alvenaria e cobertura de fibrocimento. A fábrica foi equipada com um misturador de ração, com capacidade para $300 \mathrm{~kg}$, e um triturador de milho $\mathrm{n}^{\circ} 2$, com motor elétrico de 7,5 cv.

Como o SISCAL foi implantado numa área agrícola, o preço da terra não foi incluído no custo de 
484 Rev. bras. zootec.

implantação do sistema, pois, neste caso, foi mais relevante realizar um estudo para comparar a rentabilidade da atividade agrícola x SISCAL.

A madeira utilizada para confecção das cabanas, comedouros, fábrica de ração, abrigos rústicos foi de eucalipto.

Os preços dos materiais de construção, equipamentos necessários para implantação do sistema e mão-de-obra foram coletados na região de Pato Branco - PR e convertidos para o valor do dólar comercial de venda do dia 31 de julho de 1997 (US\$1,00=R $\$ 1,0845$ ).

O cálculo do custo de implantação foi realizado por meio de planilha (EXCEL). Já o custo de produ- ção dos leitões foi realizado por intermédio do software SUICALC (GIROTTO, 1993), considerando o valor de US\$1,00 = R \$1,75, em junho/1999. O preço do quilo de suíno vendido entre 20 a $25 \mathrm{~kg}$, no mês de junho de 1999 foi de US\$ 0,748.

Com relação a mão-de-obra, foi estabelecido 2 horas diárias para a realização de todas as práticas de manejo no SISCAL.

\section{Resultados e Discussão}

O custo de implantação do SISCAL para 14 matrizes e um reprodutor, nas fases de reprodução, lactação e creche, foi de US\$ 490,20 por matriz

Tabela 1 - Custo total de implantação, para 14 matrizes e um reprodutor, no Sistema Intensivo de Suínos Criados ao Ar Livre (SISCAL), nas fases de reprodução, lactação e creche

Table 1 - Facility establishment costs for 14 sows and one boar, in Outdoor Pig Production System (SISCAL), in reproduction, lactation and nursery phases

\begin{tabular}{|c|c|c|c|}
\hline Item & $\begin{array}{l}\text { Número } \\
\text { Number }\end{array}$ & $\begin{array}{l}\text { Valor unitário } \\
\text { Unitary value } \\
\text { US\$ }\end{array}$ & $\begin{array}{l}\text { Valor total } \\
\text { Total value } \\
\text { US\$ }\end{array}$ \\
\hline \multicolumn{4}{|l|}{ Material } \\
\hline $\begin{array}{l}\text { Instalação hidráulica (há) } \\
\text { Hydraulic installation (ha) }\end{array}$ & 1,8 & 434,79 & 782,62 \\
\hline $\begin{array}{l}\text { Cerca elétrica (ha) } \\
\text { Electricfencing }(\text { ha })\end{array}$ & 1,8 & 635,733 & 1144,32 \\
\hline $\begin{array}{l}\text { Cabana para creche (und.) } \\
\text { Nursery huts (unit) }\end{array}$ & 2 & 90,835 & 181,67 \\
\hline $\begin{array}{l}\text { Cabana para maternidade (und) } \\
\text { Farrowing husts (ha) }\end{array}$ & 4 & 86,212 & 344,85 \\
\hline $\begin{array}{l}\text { Abrigo rústico (und) } \\
\text { Rustic shelter (unit) }\end{array}$ & 13 & 14,868 & 193,29 \\
\hline $\begin{array}{l}\text { Comedouro para leitões (und) } \\
\text { Feeder } 1 \text { (unit) }\end{array}$ & 4 & 34,44 & 137,76 \\
\hline $\begin{array}{l}\text { Comedouro para porca em lactação (und) } \\
\text { Feeder } 2 \text { (unit) }\end{array}$ & 2 & 30,16 & 60,32 \\
\hline $\begin{array}{l}\text { Comedouro para animal adulto (und) } \\
\text { Feeder } 3 \text { (unit) }\end{array}$ & 2 & 24,165 & 48,33 \\
\hline $\begin{array}{l}\text { Fábrica e depósito de ração (und) } \\
\text { Feed plant and storage barn (unit) }\end{array}$ & 1 & 1229,10 & 1229,10 \\
\hline $\begin{array}{l}\text { Equipamentos } \\
\text { Equipments }\end{array}$ & & & \\
\hline $\begin{array}{l}\text { Misturador de ração ( } 300 \mathrm{~kg} \text { ) (und) } \\
\text { Feed mixer ( } 300 \mathrm{~kg}) \text { (unit) }\end{array}$ & 1 & 910,98 & 910,98 \\
\hline $\begin{array}{l}\text { Triturador } \mathrm{n}^{\circ} 02 \text {, com motor elétrico (und) } \\
\text { Feed mill no } 2 \text { with electrc motor (unit) }\end{array}$ & 1 & 1225,49 & 1225,49 \\
\hline $\begin{array}{l}\text { Custo total dos materiais e equipamentos } \\
\text { Total cost of the materials and equipments } \\
\text { Mão-de-obra (homem/dia) } \\
\text { Labour (man/day) }\end{array}$ & & & 6258,73 \\
\hline $\begin{array}{l}\text { Custo da pastagem (ha) } \\
\text { Pasture cost (ha) }\end{array}$ & 1,8 & 94,41 & 169,94 \\
\hline $\begin{array}{l}\text { Custo total de implantação } \\
\text { Total cost }\end{array}$ & & & 6862,80 \\
\hline $\begin{array}{l}\text { Custo por matriz instalada } \\
\text { Cost per housed sow }\end{array}$ & & & 490,20 \\
\hline
\end{tabular}


instalada (Tabela 1). Nos resultados obtidos por DALLA COSTA et al. (1995), EDWARDS e ZANELLA (1996), DALLA COSTA e SANTOS (1996) e OLIVEIRA (1996), os custos por matriz instalada foram inferiores aos obtidos neste estudo. No entanto, o custo de implantação deste trabalho foi inferior ao observado por THORNTON (1990). Estas diferenças nos custos de implantação estão relacionadas aos tipos de materiais utilizados para a confecção das instalações e equipamentos.

Os maiores gastos no sistema foram verificados com a compra de equipamentos (misturador de ração e triturador de milho, com motor elétrico $7,5 \mathrm{cv}$ ) e a construção da fábrica e depósito de ração, os quais representaram 31,13 e $17,90 \%$ do custo total de implantação, respectivamente. Se o produtor tiver estes equipamentos e um galpão em sua propriedade, o custo de implantação será de apenas $\mathrm{R} \$ 240,35$ por porca instalada.

A instalação da cerca elétrica e da rede hidráulica corresponderam a 16,67 e 11,40\% do custo total de implantação, respectivamente. Já os gastos com as cabanas, os abrigos rústicos e os comedouros incidiram $14,08 \%$ sob custo de implantação.

Os custos das cabanas de lactação foram de US\$ 86,21 e os de creche, de US\$ 90,83. No entanto, DALLA COSTA et al. (1995) observaram valores superiores aos obtidos neste estudo. Esses autores verificaram que $78,64 \%$ dos custos das cabanas de gestação e $51,40 \%$ dos custos das cabanas de lactação foram com as chapas galvanizadas para a cobertura.

$\mathrm{O}$ custo de mão-de-obra para confecção das cabanas, abrigos rústicos, comedouros, plantio da forrageira, construção da fábrica e depósito de ração, instalação da rede hidráulica e cerca elétrica representou $6,32 \%$ do custo total de implantação.

A formação da pastagem foi o item que menos contribuiu para a elevação dos custos de implantação.

Com relação ao custo de produção, a depreciação das instalações e dos equipamentos representou $51,28 \%$ do custo fixo e a alimentação, $80,20 \%$ do custo variável (Tabela 2). Já no estudo realizado por DALLA COSTA et al. (1995), a alimentação representou $73,90 \%$ dos custos variáveis.

O custo de produção foi de US\$ 0,617 por kg de leitão produzido (Tabela 2). Com esse custo, foi possível obter $18,81 \%$ de lucro por $\mathrm{kg}$ de leitão produzido.

Se a área utilizada para produção de suínos ao ar livre ( 1,8 hectares) fosse destinada para produção agrícola, adotando rotação de culturas anuais, tais
Tabela 2 - Custo de produção do Sistema Intensivo de Suínos Criados ao Ar Livre (SISCAL)

Table 2 - Production cost of Outdoors Pig Production System (OPPS)

\begin{tabular}{cc}
\hline Item & Custos em US\$ $/ \mathrm{kg} \mathrm{de}$ \\
leitão produzido 1 \\
Costs in US $\$ / \mathrm{kg}^{1}$ of \\
produced pig ${ }^{1}$
\end{tabular}

\begin{tabular}{|c|c|}
\hline Custos fixos & \\
\hline Fixed costs & \\
\hline Depreciação das instalações & 0,020 \\
\hline Depreciation of the facilities & \\
\hline Depreciação dos equipamentos & 0,040 \\
\hline Depreciation of the equipments & \\
\hline Juros s/capital médio & 0,050 \\
\hline Interests on average capital & \\
\hline Juros s/capital reprodução & 0,002 \\
\hline Interests on reproduction capital & \\
\hline Juros s/animais estoque & 0,005 \\
\hline Interests on animal stock & \\
\hline Custos fixos médios & 0,117 \\
\hline Average fixed costs & \\
\hline Custos variáveis & \\
\hline Variable costs & \\
\hline Alimentação & 0,401 \\
\hline Feeding & \\
\hline Mão-de-obra & 0,058 \\
\hline Labor & \\
\hline Produtos veterinários & 0,002 \\
\hline Veterinary products & \\
\hline Transporte & 0,001 \\
\hline Transport & \\
\hline Energia e combustível & \\
\hline Energy and fuel & \\
\hline Manutenção e conservação & 0,009 \\
\hline Maintenance and conservation & \\
\hline INSS & 0,018 \\
\hline Eventuais & 0,009 \\
\hline Eventual & \\
\hline Custo variável médio (US\$) & 0,500 \\
\hline Average variable cost & \\
\hline Custo total médio (US\$) & 0,617 \\
\hline Total average cost & \\
\hline
\end{tabular}

${ }^{1}$ Leitões até 60 dias de idades.

1 Piglets 60 days of age.

como milho, soja, trigo e feijão, a margem líquida da exploração agrícola seria de US\$ 3148,25 e a do SISCAL, de US\$ 6747,11 (Tabela 3), durante 30 meses de atividade. Nesse caso, o produtor teria um lucro médio anual de US $\$ 2698,84$, ao produzir suínos ao ar livre, e de US $\$ 1259,30$, ao produzir cereais. DALLA COSTA et al. (1995) verificaram maior lucratividade do SISCAL/hectare que o SISCON + cultivo de milho ou feijão, em sistema de arrendamento. 
486 Rev. bras. zootec.

Tabela 3 - Resultado comparativo das culturas anuais: milho, soja, feijão e trigo, com a criação de suínos ao ar livre em 1,8 hectares, no período de janeiro de 1997 a junho de 1999

Table 3 - Comparative result of the annual cultures: corn, soybean, bean and wheat with the outdoor pig production system, in 1,8 hectares, from January of 1997 to June of 1999

\begin{tabular}{lcc}
\hline Item & $\begin{array}{c}\text { Culturas anuais } \\
\text { Annual cultures } \\
(\mathrm{US} \$)^{*}\end{array}$ & $\begin{array}{r}\text { SISCAL } \\
\text { OPPS } \\
(\mathrm{US} \$)^{1}\end{array}$ \\
\hline $\begin{array}{l}\text { Custo variável } \\
\text { Variable cost }\end{array}$ & $13.082,46$ & 9093,32 \\
$\begin{array}{l}\text { Custo fixo } \\
\text { Fixed cost }\end{array}$ & 2721,90 & 989,12 \\
$\begin{array}{l}\text { Custo total } \\
\text { Total cost }\end{array}$ & $15.804,36$ & $10.082,32$ \\
$\begin{array}{l}\text { Renda bruta } \\
\text { Gross margin }\end{array}$ & $18.952,61$ & $16.829,43$ \\
$\begin{array}{l}\text { Margem líquida } \\
\text { Net margin }\end{array}$ & 3148,25 & 6747,11 \\
\hline $\begin{array}{l}1 \\
\text { Dólar (média de } 30 \text { meses): US } \$ 1,24 .\end{array}$ & \\
Dollar (average of 30 months): US\$1.24.
\end{tabular}

Os custos fixo e variável e a margem bruta das culturas anuais avaliadas (milho, soja, trigo e feijão) foram obtidos por intermédio dos custos de produção, índices de produtividade e preços pago ao produtor estimados pela SECRETARIA DA AGRICULTURA E DO ABASTECIMENTO DO ESTADO DO PARANÁ (1999). A partir destes dados, procedeu-se à somatória dos custos e da margem bruta, durante 30 meses, período referente à duração da atividade suinícola, considerada no experimento. Portanto, no estudo da atividade agrícola, simulou-se que, no primeiro ano, seriam cultivados milho (plantio direto), feijão das águas e trigo (cultivo mínimo); no segundo ano, soja (plantio direto) e trigo (cultivo mínimo); e nos últimos seis meses, milho.

\section{Conclusões}

O SISCAL apresenta baixo custo de investimento inicial e de produção. Portanto, este tipo de sistema de criação pode ser uma alternativa viável aos produtores da região Sudoeste do Paraná.

\section{Referências Bibliográficas}

DALlA COSTA, O.A., GIROTTO, A.F., GIROTTO, A.D. et al. 1995. Análise econômica dos sistemas intensivos de suínos criados ao ar livre (SISCAL) e confinados (SISCON), nas fases de gestação e lactação. R. Soc. Bras. Zootec., 24(4):615-622.

DALLA COSTA, O.A., SANTOS FILHO, J.I. 1996. Resultados econômicos do sistema intensivo de suínos criados ao ar livre: Uma abordagem utilizando modelos de decisão. In: SIMPÓSIO SOBRE SISTEMA INTENSIVO DE SUÍNOS CRIADOS AO AR LIVRE-(SISCAL), 1, Concórdia- SC, 1996. Anais... Concórdia, 1996. p.204-221.

EDWARDS, S.A. 1994.Outdoor pig production: the European perspectiva. Pig News Informations, 15(4):111-112.

EDWARDS, S.A., ZANELLA, A.J. 1996. Produção de suínos ao ar livre, bem estar e considerações ambientais. A Hora Veterinária, (93):88-93.

GIROTTO, A.F. SUICALC- (Cálculo de custo de produção de suínos para o abate): Manual de utilização. Concórdia, SC: EMBRAPA- CNPSA, 1993. 31p. ( EMBRAPA-CNPSA, DOCUMENTOS, 30).

GOMES, M.F.M., GIROTTO, A.F., TALAMINI, D.J.D. et al. 1992. Análise prospectiva do complexo agroindustrial de suínos no Brasil. Concórdia: EMBRAPA-CNPSA. 108p. (EMBRAPA-CNPSA. Documentos, 26).

LE DENMAT, M., DAGORN, J., AUMAÎTRE, A. et al. 1995. Outdoor pig breeding in France. Pig News Information, 16(1):13-16.

McGLONE, J.J. 1996. Outdoor production and sow productivity. PIGS-Misset., 12:(3).

MORTENSEN, B., RUBY, V., PEDERSEN, B.K. et al. 1994. Outdoor pig production in Denmark. Pig News Information, 15(4):117-120.

OLIVEIRA, J.A.V. História, desenvolvimento e resultados técnicos do sistema de criação de suínos ao ar livre no Sul do Brasil. In: SIMPÓSIO SOBRE SISTEMA INTENSIVO DE SUÍNOS CRIADOS AO AR LIVRE-SISCAL, 1, 1996, Concórdia. Anais... Concórdia, 1996. p.29-34.

THORNTON, K. 1990. Producción a la intemperie: Retorno al futuro? Industria Porcina, p.6-9.

SECRETARIA DA AGRICULTURA E DO ABASTECIMENTO DO ESTADO DO PARANÁ - SEAB/PR. 1999. Prognóstico cebola. Acompanhamento da situação agropecuária do Paraná, 25(6):58-62.

SPINER. N., BRUNORI, J. 1995. Volver a Casa. Campo y Tecnologia. Córdoba, (22):64-6.

ZANELLA, A.J. Fatores que põem em risco o bem-estar de suínos ao ar livre. In: SIMPÓSIO SOBRE SISTEMA INTENSIVO DE SUÍNOS CRIADOS AO AR LIVRE - SISCAL, 1, 1996, Concórdia. Anais... Concórdia, 1996. p.157-167.

Recebido em: 28/02/00

Aceito em: 10/10/00 